\title{
Futuro del derecho del mercado financiero: regulación, desregulación, neo-regulación y soft law
}

\author{
Jaime Vintimilla Saldaña
}

\section{Resumen}

La forma como en el mundo se regulan los mercados financieros ha debido enfrentar un gran reto por la constante colisión o complementariedad existente entre soft y hard Law, entre fuentes públicas y privadas, entre ley y autorregulación. El artículo trata varios problemas y formas de abordarlos donde resulta importante considerar el incremento y creciente sofisticación de la actividad financiera así como la necesidad de contar con mercados seguros, entidades sólidas, reguladores independientes y operaciones transparentes.

Palabras claves: Mercado financiero, regulación, desregulación, neoregulación, derecho flexible.

\begin{abstract}
The way how in the world it is regulated the financial markets has had to face a great challenge due to the constant collision or complementarity between soft and hard Law, between public and private sources and between law and self-regulation. The article deals with many problems and views to tackle them where it is important to consider the growth and increasing sophistication of financial activity as well as the need for save markets, solid entities, independent regulators and transparent operations.
\end{abstract}

Key words: Financial Market, regulation, deregulation, neo-regulation, soft law.

Abogado y Doctor en Jurisprudencia por la Pontificia Universidad Católica del Ecuador, Diplomado Superior en Manejo de Conflictos por la Universidad Técnica Federico Santa María y Universidad de las Américas, Máster en Derecho, Empresa y Justicia por la Universitat de Valencia, España. Profesor en la Universidad San Francisco de Quito, árbitro y mediador. 


\section{Sumario}

I. La regulación en el derecho del mercado financiero II. La desregulación: ¿̇la causa de todos los males? III. La neoregulación: una paradoja. IV. Soft law: la revolución de las fuentes jurídicas. 1. Modalidades de la autorregulación. 2. Los códigos de conducta. V. Reflexion final.

\section{EL DERECHO DEL MERCADO FINANCIERO Y LA REGULACIÓN}

El crecimiento e importancia del mercado ha generado cambios estructurales y dogmáticos dentro del Derecho Mercantil. Como consecuencia, ha surgido el denominado Derecho del Mercado Financiero como aquella disciplina jurídica que estudia el conjunto de normas que regulan los mecanismos que permiten garantizar la eficiente asignación del ahorro a la inversión, siendo el mercado ${ }^{1}$ precisamente la herramienta cardinal que permite cumplir esta función económica².

Por esta razón, algunos juristas sostienen que incluso las fuentes y la naturaleza de este Derecho han cambiado, pues "mientras que, desde la codificación, el Derecho mercantil se presentaba como un Derecho esencialmente privado, el Derecho del mercado que ahora se gesta es un Derecho mixto, público y privado, o, mejor, un Derecho regido tanto por normas de Derecho público como por normas de Derecho privado"3.

Es decir, el mercado y sus efectos han provocado la necesidad de mantener, reformar e incorporar diversas y nuevas fuentes jurídicas al Derecho in comento, pues han cobrado importancia, ya sea porque se complementan, ya sea porque colisionan, aquellas normas del denominado Soft Law o derecho blando, las de autodisciplina o autorregulación y las normas mixtas donde confluyen lo público y privado. Seguramente a causa de este fenómeno se dice que el desarrollo por el sistema financiero de las funciones que le son propias es el resultado, no siempre plenamente alcanzado, de una decidida acción normativa que se basa en un sistema de fuentes ciertamente complejo ${ }^{4}$.

Esta realidad normativa variopinta irrefutablemente conduce a la necesidad de estudiar lo que se conoce como regulación del sistema financiero y los mercados financieros, es decir, aquella capacidad normativa para garantizar el buen funcionamiento de los mercados y la protección del inversor mediante

1 Zunzunegui define al mercado como aquel canal a través del cual el patrimonio estático que constituye el ahorro se convierte en patrimonio dinámico financiando la inversión. Su ordenación forma un sistema, el financiero, identificado como el conjunto de instituciones, entidades y operaciones a través de los cuales se canaliza el ahorro hacia la inversión, suministrando dinero $u$ otros medios de pago para financiar las actividades de los operadores económicos. En este marco se pueden distinguir, desde el punto de vista económico, tres modalidades de asignación del ahorro: una directa acudiendo al mercado de valores y otras dos indirectas, a través de la banca o del seguro. Véase Zunzunegui, F., "Regulación financiera en una economía globalizada", en ZUNZUNEGUI, F. (Director), Derecho bancario y bursátil, Colex, 2012, página 26.

2 Op. cit., página 25.

3 Menéndez, A., y Uría, R., Curso de Derecho mercantil, 2ª . ed., Ed. Thomson/Civitas, 2006, página 42.

4 Cortés, L., y Sala, A., Lecciones de Contratos y Mercados Financieros, Ed. Thomson/Civitas, 2004, páginas 33 y 35 . 
normas creadas por los interesados (autorregulación) y por la acción legislativa de los poderes públicos (heterorregulación)

En definitiva, se busca generar condiciones previas de seguridad y economía que reduzcan los riesgos y los costes de los inversores ${ }^{6}$.

Sin embargo, la regulación de la realidad financiera ha debido enfrentar varios riesgos, retos y deficiencias a causa de varios problemas latentes que han constituido una suerte de perpetuum mobile, perpetual motion o movimiento -móvil- perpetuo, en el sentido que los fallos del mercado o los excesos reguladores han generado paradojas incesantes donde se han repetido en el tiempo procesos regulatorios con distintos matices como una clara expresión de los choques entre el estado y el mercado.

Estos matices, dependiendo del tiempo, del mecanismo usado o de las fuentes creadoras de normas, han recibido la denominación de regulación, desregulación (liberalización), neoregulación y autorregulación y han debido enfrentar, entre otros, los siguientes problemas ${ }^{7}$ :

1. El incremento y creciente sofisticación de la actividad financiera ha generado nuevas instituciones, mercados e instancias de control y supervisión, ya que, de manera incesante, aparecen nuevos productos para satisfacer las necesidades de las empresas y los ahorradores.

2. La necesidad de contar con mercados seguros, entidades sólidas, reguladores independientes y operaciones transparentes.

3. Las crisis financieras demuestran la importancia de formular una buena regulación que logre un adecuado equilibrio entre los diversos intereses en juego.

4. Se requieren mecanismos de recuperación de la confianza para asegurar el buen funcionamiento de los mercados en base a la buena fe y la lealtad y para ello se requiere de una regulación protectora de la integridad y transparencia de los mercados.

5. La presencia recurrente del choque inevitable entre los operadores dominantes que velan por su propio interés y su cuenta de resultados y la del gobierno que trata de defender el interés de los consumidores finales y, a veces, la ideología imperante ${ }^{8}$.

5 Salinas Adelantado, C., "Desregulación y Neoregulación en el Mercado de Valores (1)", en Revista Derecho Mercantil, 1997, número 224, páginas 714 a 722. Véase también CORTÉS, L., y SALA, A., Op. cit., páginas 33 a 38

6 Cortéz, L., y SALA, A., Op. cit., páginas. 33 y 34.

7 Hernández-Gil, A., “Prólogo”, en ZUNZUNEGUI, F. (Director), Derecho bancario y bursátil, Colex, 2012, página 23

8 En el caso ecuatoriano está en ciernes un nuevo intervencionismo estatal, pues descontento con la desaceleración en las operaciones de la banca privada, el Gobierno impulsa un nuevo ordenamiento o código orgánico monetario y financiero que busca integrar de manera definitiva a la banca privada con sus objetivos de política 
De todos modos, la forma para manejar y solucionar estos problemas se ha concentrado en la necesidad de formular normas, aunque desafortunadamente si no son redactadas de forma adecuada no serán tampoco la panacea, sino, al contrario, se convertirán en la causa directa para propagar la inseguridad y la falta de garantía de un funcionamiento eficiente del mercado ${ }^{\text {. }}$ En definitiva, las normas serán también las que ocasionen las distintas crisis financieras si no van acompañadas de una "red de seguridad" con tres pilares: la regulación, la supervisión y el tratamiento de las situaciones de crisis ${ }^{10}$.

\title{
II. LA DESREGULACIÓN: ¿LA CAUSA DE TODOS LOS MALES?
}

\author{
La desregulación es un fenómeno complejo compuesto por tres componen- \\ tes: uno político, otro jurídico ${ }^{11}$ y un último económico.
}

En lo político ha existido una confusión terminológica y conceptual con privatización y desburocratización que, a pesar de que la doctrina no es pacífica, no resultan ser sinónimos. ${ }^{12}$

En lo jurídico, su análisis ha sido de reciente data por parte de los tratadistas tanto del Derecho mercantil como del Derecho administrativo, pues la desregulación más ha constituido un tema principalmente estudiado por los economistas, ${ }^{13}$ aunque algunos relacionan la intervención administrativa con

económica. Será responsabilidad de la nueva Junta de Política y Regulación Monetaria y Financiera el establecer los niveles de crédito, tasas de interés, encajes y provisiones aplicables. Además esta norma de lege ferenda otorgará amplios poderes a la Función Ejecutiva para formular políticas y regulaciones en materia monetaria, crediticia, cambiaria y financiera así como de seguros y valores. Véase Acosta Burneo, A., "¿Estado será el nuevo administrador bancario?", en Comercio, Revista de la Cámara de Comercio de Guayaquil, febrero 2014, páginas 18 y 19, disponible en http://www.lacamara.org/website/attachments/article/776/RevFeb2014.pdf. [Fecha de visita 23/03/2014].

9 El Director de Estudios de Financieros en el Cato Institute sostiene que "las últimas décadas han presenciado una expansión significativa en el número de regulaciones y reguladores financieros, a diferencia de lo que se asevera frecuentemente de que nuestras regulaciones financieras habían sido "desmanteladas". Si bien es posible que muchos reguladores hayan sido cortoplacistas o que confiaron demasiado en su habilidad de salvar del colapso a nuestros mercados financieros, dichos defectos son atribuibles a la regulación, y no a la desregulación. Cuando uno escarba la superficie del argumento de la "desregulación", se vuelve evidente que los supuestos culpables, como la Ley Gramm-Leach-Bliley, no causaron la actual crisis y que la supuesta negativa de los reguladores de confrontar los derivados y las hipotecas "rapaces" habría tenido poco impacto en la manera en que se desarrollaron las cosas, ya que estos asuntos no se encontraban en el centro de la crisis. Para explicar la crisis financiera, y evitar la siguiente, debemos analizar el fracaso de la regulación, no el de una mítica desregulación". Véase CALABRIA, M., ¿Fue la desregulación la causante de la crisis financiera?, en http://www.elcato.org/fue-la-desregulacion-lacausante-de-la-crisis-financiera. [Fecha de visita 23/03/2014].

10 ZUNZUNEGUI, F., op. cit., página 28.

11 SALINAS ADELANTADO, C., op. cit., página 710.

12 La desburocratización es la disminución del volumen e importancia de las "normas jurídicas", ya sean estatales, ya sean de autorregulación, en una determinada actividad. En cambio, la privatización puede entenderse de dos formas: a) Privatización en sentido formal, que es la sujeción de determinadas actividades desarrolladas por los poderes públicos al Derecho común; y, b) Privatización en sentido material, que consiste en la traslación, total o parcial, al sector privado de actividades empresariales que hasta dicho momento eran desempeñadas por los poderes públicos. Véase Salinas Adelantado, C., op. cit., pág. 713 y De La Serna Bilbao, M., La privatización en España, Aranzadi, 1995, páginas 40 y 66.

13 Por ejemplo en Ecuador algunos economistas ya defendían en el año 2008 que el país "dio paso a una profunda liberalización financiera: la apertura de la cuenta de capitales en el país llegó incluso a superar los niveles que se habían dado en Chile y Bolivia. Lo cual, unido a un irresponsable proceso de desregulación financiera que minimizó los controles sobre la banca, fue debilitando el ya frágil aparato financiero nacional. En este contexto de liberalización y desregulación financiera, apoyado por el FMI, se dio paso al salvataje bancario, con un costo 
la desregulación como una tendencia de evolución en el Derecho mercantil, ${ }^{14}$ en el sentido de que junto al incremento de la normativa ordenadora se aprecia en la actualidad un claro fenómeno de desregulación y liberalización de la actividad económica, como mecanismos que ponen de relieve la inhibición o "retraimiento de la acción directa del Estado en la economía, comportando el abandono por el Estado de su condición de agente económico en ciertos sectores antes reservados para sí en exclusiva (monopolios) y, por tanto, la apertura a la acción de los particulares." ${ }^{15}$

Finalmente, en lo económico la mirada se fija en la paz financiera de cada empresa (estabilidad microeconómica) y del sistema en su conjunto (estabilidad macroeconómica) así como en la necesidad de que se protejan las inversiones y los intereses de los prestatarios y ahorradores. En definitiva, la desregulación no debe alejarse de un equilibrio entre una regulación que no impida la iniciativa empresarial y un nivel de control que garantice la seguridad de los fondos de todos los depositantes ${ }^{16}$. La idea es construir un espacio de compatibilidad entre el intervencionismo estatal y la economía libre.

Así las cosas, se puede definir a la desregulación como la eliminación, modificación o simplificación, por parte de los poderes públicos, de aquellas normas o trámites administrativos que de alguna manera limiten, condicionen o restrinjan la iniciativa y el desarrollo de las actividades de contenido económico tanto públicas como privadas. ${ }^{17}$

Como se ha advertido ya, el proceso de desregulación requiere de una previa regulación que debe ser reformada por el hecho de presentar trabas jurídicas y barreras administrativas injustificadas a la libertad de establecimientos y de prestación de servicios, inclusive se hablaba del engrosamiento innecesario del estado, siendo necesario, entonces, reducir su tamaño.

Sin embargo, a algunos procesos desregulatorios se les acusa de todos los males como ser los causantes de las crisis financieras mexicana y asiática (1994 1997), de la quiebra de empresas Enron, World Com (2001/02) y de las hipotecas subprime (2007/09)- burbuja inmobiliaria-.

Por otro lado, se dice que también son los culpables de las crisis de sobreendeudamiento y desaparición de bancos de inversión así como de la debilidad del sistema financiero para medir y prevenir el riesgo.

enorme para el país, cerca de seis mil millones de dólares, en términos netos; salvataje apoyado y alentado por un banco Mundial adormilado por la ortodoxia neoliberal y carente de iniciativas". Véase Acosta Espinosa, A., El "buen vivir" para la construcción de alternativas, 2008, pág. 5, en http://www.casa.cult.cu/publicaciones/revistacasa/251/ flechas.pdf. [Fecha de visita 23/03/2014]. Sin embargo, son escasos los acercamientos jurídicos del tema, aunque algo se ha intentado desde el denominado Derecho Económico.

14 Broseta Pont, M., Y Martínez Sanz, F., Manual de Derecho Mercantil, Volumen I, Tecnos, 2011, página 61.

15 Massaguer, J., "El Derecho mercantil ante las transformaciones político-sociales. Una aproximación”, en Estudios Jurídicos Homenaje a Aurelio Menéndez, Civitas, 1996, páginas 415 y ss.

16 Acosta BurneO, A., op. cit., página 19.

17 De La Serna Bilbao, M., op. cit., página 41. 
Es más, se sostiene que a partir del proceso de desregulación e innovación financiera y con el desarrollo de una nueva ingeniería financiera, los mercados se han vuelto más inestables y volátiles provocando nuevos escenarios de crisis en regiones y países así como quiebras en conglomerados financieros y no financieros. ${ }^{18}$

Para guardar consonancia con la explicación anterior, bien vale la pena traer a colación diversos ejemplos ocurridos en el mercado bancario y en el bursátil así como una breve alusión de lo acaecido en España en el mercado de valores.

En el primer caso, la derogación de la ley norteamericana Glass-Steagall en noviembre de 1999 que separaba la banca de inversiones (que organizan la venta de bonos y acciones) y la comercial (que se prestan dinero) es una muestra de desregulación, pues eliminó la prohibición legal de combinación entre bancos comerciales y bancos de inversión. Lamentablemente, el error, deliberado o no, fue el hecho que los autores de la ley no se proponían establecer un sistema regulador que supervisara las empresas que combinaban la banca comercial y de inversión, pues sencillamente prohibieron la combinación de dichas empresas. En conclusión, la desregulación financiera no reformó adecuadamente la realidad del mercado, pues permitió que la banca de inversión emulara el método de apuestas especulativas de alto riesgo. ${ }^{19}$

En el mercado bursátil, en cambio, la Comisión de Bolsa y valores de los EEUU (SEC por sus siglas en inglés) permite en abril de 2004 que los grandes bancos de inversión pidieran aumentar su ratio de deuda sobre capital (de 12:1 a 30:1 o superior) para que así pudieran comprar más títulos respaldados por hipotecas, inflando la burbuja de la vivienda en el proceso. La SEC defendió las virtudes de la autorregulación: juez y parte en el control de excesos, pero en realidad la norma de 2004 fortaleció la supervisión de los mercados de valores.

Por último, en España se tiene un ejemplo en el mercado bursátil, pues la desregulación realizada con la Ley de Mercado de Valores LMV de 1988 tenía un objetivo más dentro de la finalidad primordial que se perseguía, que era la modernización del ordenamiento español, y por otro lado, que ésta se ha desarrollado de una forma muy parecida a la francesa, ya que se basa en la existencia de un fuerte órgano de vigilancia, y en un escaso reconocimiento de

18 Soto EsquiveL, R., “Desregulación financiera y finanzas públicas en México”, en Economía Informa, 2010, número 362, enero-febrero, pág. 49, en http://www.economia.unam.mx/publicaciones/econinforma/pdfs/362/05robertosoto. pdf. [Fecha de visita 23/03/2014].

19 La ley Gramm-Leach-Bliley o norma derogatoria de la ley Glass Steagall ha sido presentada tanto por sus defensores como por sus detractores como una revolución en cuanto a servicios financieros. Sin embargo, la ley en sí tuvo poco impacto sobre las actividades comerciales de los bancos de inversión. Las actividades fuera del balance general de Bear Stearns y Lehman Brothers eran permitidas antes de que esa ley se aprobara. Ni tampoco estas actividades comerciales socavaron a algún banco comercial afiliado ya que Bear y Lehman no tenían bancos comerciales afiliados. Adicionalmente, esos grandes bancos que sí combinaron la banca de inversión con la comercial han sobrevivido a la crisis de mejor forma que aquellos que no lo hicieron. Véase CALABRIA, M., op. cit. 
la autoregulación ${ }^{20}$. Además, no hay apenas preocupación por evitar el peligro de la burocratización. ${ }^{21}$

\section{LA NEOREGULACIÓN: UNA PARADOJA}

A la neoregulación también se la conoce como reregulación y hace alusión a los tipos de reglas de juego que deben respetar todos aquellos que quieran actuar en el mercado. ${ }^{22}$

Por ello, algunos juristas sostienen, cuando se refieren a la ley mercantil, que el universo de poderes públicos "legisladores" revela otra importante característica del Derecho Mercantil actual, que es la de ser un Derecho privado intensamente regulado, lo cual, después de la "desregulación", constituye una verdadera paradoja. ${ }^{23}$

Esta nueva regulación o "neorregulación" destaca en el Mercado Financiero, en sus tres subsectores: bancario, mercado de valores y seguros; así como también en las telecomunicaciones y radiotelevisión; en las energías; en el medicamento y servicio sanitario, entre otros.

A diferencia de la etapa anterior a la desregulación, esta "neoregulación" ya no está integrada por normas administrativas o verticales, sino por normas de naturaleza jurídico-privada, aplicables a las relaciones "inter privatos" u horizontales, que conllevan sanciones de Derecho privado, en especial, la nulidad o ineficacia del negocio jurídico ( además de incluir instituciones de Derecho administrativo complementarias: autorizaciones, autoridades de control, y régimen disciplinario administrativo. ${ }^{24}$

En definitiva, esta reregulación ha transformado las fuentes jurídicas del Derecho de Mercados Financieros, pues a lado de las normas estatales ha empezado a recobrar fuerza el denominado Soft Law o derecho blando en forma de autoregulación, ${ }^{25}$ aspecto que se analizará posteriormente. No obstante,

20 Salinas Adelantado, C., op. cit., páginas. 741 y 768.

21 Es un fenómeno contrario a la desburocratización, es decir, se refiere a aquella consecuencia que genera la desregulación de que no únicamente existe una eliminación de normas, sino su sustitución por otras nuevas, a lo que agregaría, no necesariamente mejores. La consecuencia de la burocratización es el aumento, muchas veces desmedido e inoportuno, de normas jurídicas estatales y hasta de normas de autodisciplina o autoreguladoras. Véase Salinas Adelantado, C., op. cit., pág. 711 y 749 . A mi juicio, otro aspecto relacionado con la burocratización es el aumento de presupuesto y de funcionarios, tal y como se puede apreciar con la cantidad de personas que trabajan en las agencias de regulación financiera. Así en Estados Unidos lo asignado para gastos por regulación bancaria y financiera aumentó de únicamente $\$ 190$ millones en 1960 a $\$ 1.900$ millones en 2000 y a más de $\$ 2.300$ millones en 2008 (en dólares constantes de 2000), lo mismo se puede decir de la SEC o ente encargado de regular a Wall Street. Véase Calabria, M., op. cit.

22 Salinas Adelantado, C., op. cit., pág. 712. Sin embargo, lo más adecuado es neoregulación, ya que se trata no solo de volver a regular algo, sino más bien se busca regular los mercados con nuevas visiones y fines distintos de lo que la regulación anterior estableció, considerando los resultados obtenidos previamente.

23 Vicent Chuliá, F., Introducción al Derecho Mercantil, Manuales Tirant lo Blanch, 2008, página 89.

24 Op. cit., página 89.

25 No se puede olvidar que en países como Gran Bretaña dentro de los mercados de valores la única regulación existente era la self regulation que se daban los propios interesados. 
una visión realista y moderna obliga a prestarle más atención, en especial incluyendo el estudio de las normas reglamentarias y de la "soft Law" o autorregulación. ${ }^{26}$

De todas formas, la neoregulación se ha orientado a establecer nuevas reglas de juego y estándares mínimos de comportamiento de los operadores mercantiles buscando el equilibrio de los principios de eficiencia, de estabilidad y de transparencia para obtener la seguridad y la garantía del funcionamiento eficiente del mercado ${ }^{27}$ en un nuevo entorno, donde la dirección pública del sector se compagina y no sustituye la confianza que inspiran los derechos constitucionales vigentes en el mercado. Como ya se dijo, para ello el derecho privado, el derecho público y la autoregulación cooperan para que los operadores financieros no solamente compitan sino que lo hagan con responsabilidad social.

Sin embargo, presenta también una serie de riesgos que es necesario conocer para poder evitarlos o resolverlos oportunamente. Entre ellos, el peligro de la burocratización y la posibilidad de que los cambios estructurales y normativos no tengan efecto y generen una nueva crisis son los más peligrosos y acuciantes. Por eso, resulta imprescindible evitar que se dicten normas abundantes y sin coordinación así como no pueden nacer desde la teoría y sin conocimiento práctico. Una propuesta para lograrlo es la necesidad de utilizar mecanismos de producción normativa más flexibles, pero que no pierdan por ello garantías para sus destinatarios. ${ }^{28}$

\section{SOFT LAW: LA REVOLUCIÓN DE LAS FUENTES JURÍDICAS}

Siguiendo al profesor italiano Stefano Rodotá, se puede advertir que las transformaciones de los sistemas jurídicos se relacionan con la existencia de una revolución o explosión de las fuentes del Derecho ${ }^{29}$. Hoy en día, el sistema de fuentes del Derecho refleja una nueva distribución del poder político y una jerarquía social diversa, pues la heurística jurídica es multilevel y multistakeholder con múltiples disciplinas y actores diversos.

Así a lo largo de la historia se puede advertir que siempre han existido sujetos públicos y sujetos particulares que ha generan reglas propias.

Hoy en día gracias a varios fenómenos interconectados como la globalización,

27 Zunzunegul, F., op. cit., páginas 31 y 32. Véase también ZUNZUNEGUI, F., Derecho del Mercado Financiero, Marcial Pons, 2005, páginas 35-40.

28 Salinas Adelantado, C., op. cit., página 773.

29 Rodota, S., "Códigos de Conducta: entre Hard Law y Soft Law", en REAL PÉREZ, A. (coord.), Códigos de conducta y actividad económica: una perspectiva jurídica. I y II Congresos Internacionales "Códigos de conducta y mercado", Facultad de Derecho, Universidad Complutense de Madrid, Marcial Pons, 2010, página 19. 
la innovación científica y tecnológica, la tendencia a la uniformidad normativa, el comercio internacional, la defensa de los derechos humanos, el cambio climático, etc., se encuentran diversos tipos de normas: internacionales, supranacionales, nacionales, subnacionales, anacionales, etc que regulan varias actividades, de las cuales no se escapa ni el mercado ni la economía globalizada.

Es en esta maraña normativa donde precisamente surge el soft law o droit assourdi ante la estructura rígida de la norma y la inadecuación de determinados instrumentos internacionales.

En principio el soft law, weak law o derecho flexible, dúctil, maleable o blando surge en el contexto de las fuentes del derecho internacional tanto público como privado y representan a un movimiento de flexibilización de las fuentes que apunta a un desarrollo más flexible del Derecho por parte del propio legislador y a unas normas abiertas (open texture) para el juez, que empieza a aceptar también instrumentos, soportes o fuentes blandos.

El soft law es un concepto particularmente operativo en el Derecho Internacional Público, y en él se incluyen recomendaciones, dictámenes, códigos de conducta, principios, etc., sin poder de vinculación directa, pero que influyen no sólo en el desarrollo legislativo futuro, sino como referentes específicos en la actuación judicial.

También existe un soft law directamente aplicable al Derecho Internacional Privado y se lo advierte en la proliferación de leyes-modelo elaboradas en foros internacionales, algunos actos normativos característicos del Derecho Institucional, convenios internacionales disponibles por las partes o la propia fuerza ejemplificativa de determinados convenios internacionales, que actúan como fuentes a menudo en sentido impropio, pueden ser tenidas en cuenta tanto por el legislador, como, indirectamente, por el intérprete. ${ }^{30}$

En materia de derecho mercantil, en cambio, se identifica al soft law con la figura de la autorregulación o autodisciplina que busca no solo reemplazar a las normas rígidas imperantes sino que trata de que los operadores puedan también disciplinar el mercado desde su contexto, por ello no se ha concluido todavía que exista incompatibilidad entre las fuentes públicas y las privadas, entre ley y autorregulación, entre hard y soft law ${ }^{31}$. Al contrario, se ha transitado desde una convivencia con sobresaltos o colisión de fuentes hacia una complementariedad entre autoridad y libertad, donde el soft law se ha transformado en una suerte de fusible o nexo entre la ley y la autorregulación, ya no solo en el contexto internacional, sino que ahora ha invadido las realidades jurídicas nacionales.

30 Fernández Rozas, J., El Derecho del Comercio Internacional en el contorno de la globalización, Escriva. Revista del Colegio de Notarios del Estado de México, $n^{\circ} 5$, 2000, pág. 18, en http://eprints.ucm.es/6869/1/EL_DERECHO_DEL_COMERCIO_INTERNACIONAL_EN_LA_GLOBALIZACION.pdf. [Fecha de visita 24/03/2014].

31 Rodota, S., op. cit., página 21. 


\section{MODALIDADES DE LA AUTORREGULACIÓN}

El mercado no funciona por sí solo, sino que son necesarias normas jurídicas que lo regulen o disciplinen. Esta es la misma conclusión a la que han desembocado los distintos procedimientos de regulación, de desregulación y de neoregulación: nuevas normas que se incorporan no solamente desde el estado sino desde los propios operadores que conocen la rama del mercado que regulan.

Así aparece la autorregulación como regulación jurídica ${ }^{32}$ donde las normas que pertenecen al terreno de la autonomía de la voluntad y de la especialidad no se encierran solo en el ámbito de la ética sino que gozan de una naturaleza propiamente jurídica-normativa, ya que producen efectos similares a los legales o jurídicos ${ }^{33}$, pues de otra forma, aquella pura autorregulación cuyo incumplimiento no acarreara consecuencia alguna, no valdría la pena de ser catalogada de "regulación" de ningún tipo, ${ }^{34}$ ya que también se ha superado aquel principio de soft law denominado "cumple o explica". ${ }^{35}$

Es más hoy se habla del papel de la autorregulación internacional, pues la complejidad de los nuevos productos y mercados desborda la capacidad de los reguladores nacionales para ordenar la vida financiera y se hace necesario contar con la industria y sus asociaciones en la ordenación financiera. Esta realidad ha sido reconocida por los estados y los organismos internacionales que han asumido como propios los estándares y las mejores prácticas de la industria financiera. En conclusión, gracias a una autorregulación regulada se convierte la regla privada en norma pública. ${ }^{36}$

Bajo estas circunstancias, el debate existente entre autorregulación y regulación estatal (entre sistemas de regulación estatal o gubernamental y de regulación voluntaria) como alternativas excluyentes constituye un falso e innecesario debate, ${ }^{37}$ pues el mercado y todos los ahorradores, prestatarios, sujetos, instrumentos y contratos necesitan de la convergencia coordinada de los modelos de regulación.

32 De La Cuesta Rute, J., "La autorregulación como regulación jurídica”, en Real Pérez, A. (coord.), op. cit., páginas 31 a 54 .

33 Duprat, J., "Los códigos de conducta vistos por un jurista francés”, en Real Pérez, A. (coord.), op. cit., página 63.

34 Díaz Ruíz, E., "Códigos de conducta y mercados financieros: cuestiones generales", en Real Pérez, A. (coord.), op. cit., página 265 .

35 En concreto, el actual Código en "vigor" en España, el "Código Unificado", se establece sobre el principio de "cumplir o explicar" (cfr.art. 116 LMV). Sin embargo, numerosas exigencias de dicho código han sido expresamente recogidas en normas positivas, tanto reguladoras de las sociedades cotizadas, como de la propia forma societaria concreta, la sociedad anónima. Véase Santillán Fraile, I., "Algunos mecanismos de incidencia en el buen gobierno de entidades que operan en los mercados financieros", en Real Pérez, A. (coord.), op. cit., pág. 297.

36 Zunzunegui, F., op. cit., página 44.

37 Esteban Velasco, G., "Una aproximación a los códigos de buen gobierno en el marco del complejo y heterogéneo fenómeno de los códigos de conducta", en REAL PÉREZ, A. (coord.), op. cit., página 277. 
Se observa, entonces, que se hace necesario una participación de los sectores regulados (a los que se les aplica la norma) con la presencia de reglas jurídicas flexibles, experimentales, homeostáticas, es decir, la legislación negociada o contratada, donde los actores pasivos deben ser consultados, ${ }^{38}$ se transforman en herramientas capaces de evitar intervenciones legislativas tardías así como reclaman una legislación oportuna y no excesiva o hipertrófica.

Como se ha dicho ut supra, mediante el sistema de autorregulación regulada se puede alcanzar una mejor ordenación del mercado financiero. Para lograrlo, la autodisciplina financiera ha adoptado varias modalidades que van desde los códigos de conducta de la industria, a reglas técnicas o de mejores prácticas profesionales. ${ }^{39}$

Es decir, la categoría del soft law en lo financiero, no es para nada homogénea, aunque se advierte la existencia de códigos de conducta, que, a su vez, se inclinan a establecer una dicotomía entre los códigos de buen gobierno o gobernanza que se van imponiendo en el ámbito de las sociedades, especialmente cotizadas en Bolsa, y los códigos de conducta que se afirman con referencia a la publicidad por motivos de protección de los intereses económicos de consumidores y, en general, de prevención contra la competencia desleal, entre otras cosas semejantes. ${ }^{40}$

Entonces, a partir de las normas y principios legales deben ser las propias empresas o particulares quienes se autorregulen, desarrollando con la necesaria minuciosidad aquellas normas legales y creando otras que las complementen. Son los mismos interesados los creadores normativos y su presencia es trascendental para contrarrestar el poder de la industria y mejorar la eficiencia del sistema de supervisión financiera. ${ }^{41}$

\section{LOS CÓDIGOS DE CONDUCTA}

Antes de nada hay que diferenciar a los códigos de conducta de los reglamentos internos o particulares de conducta que pueden establecer determinados empresarios, que tienen o bien carácter organizativo puramente interno, establecidos y modificados a voluntad y que tienen una finalidad promocional, o bien, que constituyen parte de las condiciones contractuales que se ofrecen a la clientela. ${ }^{42}$

En todo código de conducta existe el carácter de aplicación plural, siendo los

38 Rodota, S., op. cit., página 21.

39 Zunzunegui, F., op. cit., página 44.

40 De La Cuesta Rute, J., op. cit., página 40.

41 Zunzunegui, F., op. cit., página 46.

42 Díaz Ruíz, E., op. cit., página 266. 
obligados varios sujetos. Así se puede decir que estos instrumentos de soft law, denominados también como "códigos de buenas prácticas" o "códigos tipo" han sido usados en varios sentidos, entre ellos, el jurídico. ${ }^{43}$

Entre sus acepciones se pueden encontrar cuatro orientaciones, ${ }^{44}$ a saber:

a) Reglas diversas que rigen comportamientos de personas sin vincular jurídicamente, tal es el caso de las normas meramente sociales.

b) Reglas que ya están contenidas en normas jurídicas, luego por ello tienen la naturaleza de éstas, son de obligado cumplimiento y surten mismos efectos que las normas jurídicas.

c) Son homologados por los poderes públicos, quienes conceden estímulos a quienes los cumplen, aún sin sancionar a los que no los suscriben.

d) Normas de comportamiento no exigidas por la ley, pero voluntariamente establecidas por los interesados, quienes otorgan publicidad a su compromiso de actuar conforme a esas reglas, generando en los terceros confianza de que procederán de acuerdo a las disposiciones o reglas que hacen públicas. ${ }^{45}$

Por eso, se dice que un código de conducta es una norma distinta, con propia personalidad, no identificable con las fuentes clásicas del derecho, pero muy cercano a los instrumentos contractuales y que sirve para regular, ya que permite la regulación por otros mecanismos, tratando de disciplinar el modo en que las entidades deben realizar ciertas actividades que les son propias. ${ }^{46}$

Hoy en día es muy fácil encontrar estos códigos y algunos bancos españoles, por ejemplo, han dado prevalencia al comportamiento ético y a la integralidad personal y profesional como forma de entender y desarrollar la actividad bancaria. ${ }^{47}$ Otros, al lado del catálogo de principios éticos y normas de conducta que han de regir la actuación de todos los ejecutivos y empleados rige también un código de conducta especializado en un mercado financiero, tal es el caso de los códigos de conducta en los mercados de valores. ${ }^{48}$

43 Real Pérez, A., “Presentación”, en Real Pérez, A. (coord.), op. cit., página. 12.

44 Op. cit., página 13.

45 La profesora Real insiste en que se genera en el tráfico un buen nombre y reputación del que se somete a los "códigos de conducta", que mueve a otras personas a preferir contratar-o en general relacionarse- con quienes los suscriben. Esta acepción tiene trascendencia en la Unión Europea que impulsa la suscripción empresarial de códigos de conducta. Véase op. cit., página 13.

46 Uría Fernández, F., "Códigos de conducta en el ámbito de la actividad bancaria", REAL PÉREZ, A. (coord.), op. cit., página. 311.

47 Véase el código de conducta del grupo BBVA: http://www.bbva.com/TLBB/fbinesp/codigo_conducta_bbva_ nuevo.pdf.

48 Un ejemplo es el Banco Santander. Véase su página web: http://www.santander.com/csgs/ Satellite?appID=santander.wc. CFWCSancomQP01\&c=GSInformacion\&canal=CSCORP\&cid=1278677208635\&e 
Este fenómeno se ha universalizado y bien se puede encontrar este tipo de reglas en instituciones financieras y empresariales en América Latina y, en general, en todo el mundo, aunque en algunos como en el caso ecuatoriano, en su mayoría, se habla de códigos de ética. ${ }^{49}$

En conclusión, los códigos de conducta tienen el propósito de unificar y otorgar certeza a unas normas a las que se considera debe sujetar su acción todos los que practiquen determinada actividad u ocupen una determinada posición en la sociedad financiera, pues tienen trascendencia para cualquier mercado, incluido el bursátil..$^{50}$

\section{REFLEXIÓN FINAL}

Con claridad se ha advertido el carácter jurídico de las normas de la autorregulación o autodisciplina donde son los propios interesados y los mismos operadores financieros los creadores normativos tanto de los códigos de buen gobierno como de aquellos códigos de conducta. Sin duda, marcan el futuro del Derecho del mercado financiero.

El lugar donde los códigos de conducta van a mostrar su eficacia es precisamente el mercado, en especial, cuando se hayan transformado en una expresión jurídica que demuestre que los tiempos de neoregulación y desregulación han sido positivos para evitar nuevas crisis financieras y de confianza de los ahorristas y prestatarios.

49 El Banco del Pacífico tiene un código de ética y conducta, en cambio los bancos Bolivariano y Guayaquil cuentan con códigos de ética. Véase https://www.bancodelpacifico.com/files/PDF/Gobierno\%20Corporativo/CODIGO\%20DE\%20ETICA\%20CAMBIOSCGC\%2026-03-13\%20CETICA\%205-04-13\%20DIRECTORIO\%2029-0

50 De la Cuesta Rute hace una interesante diferencia entre códigos de buen gobierno y códigos de conducta. Véase De La Cuesta Rute, J., op. cit., página 41. 